amounts calculated to give the above proportions after firing.

The gold film is applied to Inconel as substrate separated by a diffusion barrier of cerium oxide (16). The resulting laminate is stable at $750^{\circ} \mathrm{C}$ on Inconel for thousands of hours, both in air and in vacuum equivalent to that found in space. This is not the thermal limit of the film itself but it is the limit of the diffusion barrier material, cerium oxide.

The spectral reflection of the composite gold film is shown in the diagram, which also shows for comparison the spectral reflection of a "pure" gold film. Both films are 1000 Ångstroms thick and have zero transmission. The pure gold film has been prepared from an organometallic solution producing a conventional bright gold film. Although this film contains only 95 per cent gold-it contains among other constituents also a trace of rhodium to impart thermal stability-the measured reflectivity is in fair agreement with literature data for pure gold surfaces which have recently been reviewed by Loebich in this journal (17).

It is significant that the composite film developed as a selective solar absorber has a minimum reflection at a wavelength of 0.5 microns which is the wavelength of maximum solar radiation. In the near infra-red this film has low emissivity, essentially equal to that of pure gold.

A number of changes were made in the composition of the composite film in an effort toward ideal optical properties. Increased $\mathrm{BaO}$ or $\mathrm{SiO}_{2}$ contents were found to cause decreased reflection; increased $\mathrm{Cr}_{2} \mathrm{O}_{3}$ caused increased reflection.
The absorption maximum of the solar absorber film near 0.5 microns was further improved by use of a quarter wavelength antireflection coating of alumina. By use of an optically-interfering layer the reflectance of the energy-absorbing film underneath is materially reduced over a narrow wavelength band. Furthermore, an outer interfering layer of alumina likewise has the required thermal stability (18). This antireflection coating was also applied by the organometallic solution method.

\section{References}

1 R. M. Van Vliet, "Coatings for the Aerospace Environment", WADD Technical Report 60-773, 1961

$2 \mathrm{H}$. Tabor, Israel Patent 10,573, 1957

3 G. Hass, H. H. Schroeder and A. F. Turner, F. Opt. Soc. Am., 1956, 46, 31

4 D. J. Close, CSIRO Eng. Sec., Report E.D. 7, Melbourne (June 1962)

5 B. O. Seraphin, "Research Applied to Solar-Thermal Power Systems", Quarterly Progress Report Jan. 1 to March 31, 1974 under NSF/RANN Grant GI-36731X

6 R. C. Langley, "Gold Coatings for Temperature Control in Space Exploration", Gold Bull., 1971, 4, (4), 62

7 R. G. Finch, "Gold in Thick Film Hybrid Microelectronics", Gold Bull., 1972, 5, (2), 26

8 H. M. Fitch, U.S. Patent 2,984,575, 1961

9 H. M. Fitch, U.S. Patent 2,994,614, 1961

10 H. M. Fitch, U.S. Patent 3,163,665, 1964

11 H. M. Fitch, U.S. Patent 3,262,790, 1966

12 R. C. Langley and H. M. Fitch, U.S. Patent 3,313,632, 1967

13 R. C. Langley, U.S. Patent 3,573,970, 1971

14 R. C. Langley, U.S. Patent 3,445,662, 1969

15 R. C. Langley, U.S. Patent 3,363,090, 1968

16 R. C. Langley, U.S. Patent 3,176,678, 1965

17 O. Loebich, "The Optical Properties of Gold", Gold Bull., 1972, 5, (1), 2

18 R. C. Langley, U.S. Patent $3,176,679,1965$

\title{
Expanded Metal Dental Reinforcements
}

Traditionally reinforcements for dental palates have been fabricated in a 75 per cent gold alloy in the form of gauze woven from 0.005 inch diameter wire. An innovation by Engelhard Industries of London is the supply of such reinforcements in expanded metal. Manufactured by the Expanded Metal Company, London, the newer type of reinforcement provides a more economical product, the greater strength of the expanded metal allowing the palate to be thinner. While two thicknesses of gauze were formerly required for strength, only one piece of expanded metal is necessary, while a further advantage is the absence of frayed edges. It is also cheaper to produce.

Expanded metal is produced from sheet by a continuous shear and press operation. It is easily formed to shape and offers a wider range of strand widths, thicknesses and aperture sizes, so that a mesh can be chosen to suit any individual application.

Other possibilities for the use of gold alloys in this form include applications where their complete resistance to corrosion is required, coupled with their high conductivity and the rapid dissipation of heat characteristic of expanded metal.

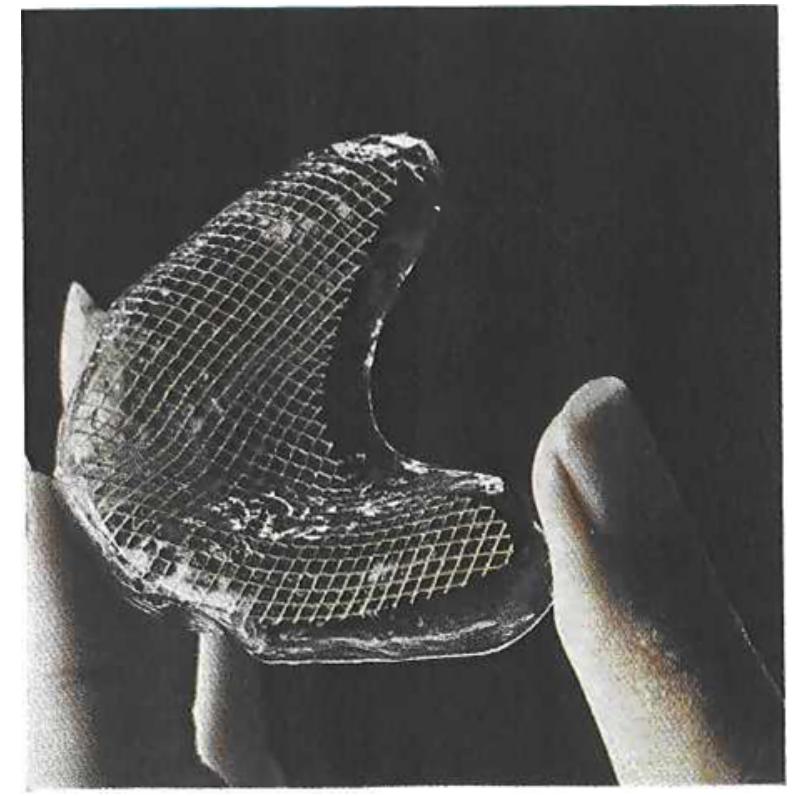

